\title{
INTERPRETAÇÃO E ANÁLISE DAS CLÁUSULAS DE EXCLUSIVIDADE NOS CONTRATOS DE COOPERAÇÃO TECNOLÓGICA
}

\section{INTERPRETATION AND ANALYSIS OF EXCLUSIVITY CLAUSE IN THE CONTRACTS OF TECHNOLOGICAL COOPERATION}

\author{
${ }^{1}$ Marcos Vinício Chein Feres \\ ${ }^{2}$ Matheus Andrade Oliveira
}

\section{RESUMO}

O presente artigo pretende analisar como as mudanças ocorridas na lei 10.973, pela Lei 13.243, alteraram a regulação dos Contratos de Cooperação Tecnológica em relação às cláusulas de exclusividades. Utilizando-se do método da microanálise institucional e do marco teórico do Direito como Identidade, resultado da aproximação da teoria de identidade do self de Taylor com as ideias de Dworkin sobre a integridade no Direito, realiza-se esta análise que visa compreender os Contratos de Cooperação Tecnológica como meio de desenvolver o sistema de inovação nacional em conformidade com os princípios de uma comunidade personificada constitucionalmente articulados.

Palavras-chave: Contratos de cooperação tecnológica, Transferência de tecnologia, Lei de inovação tecnológica, Direito como identidade

\begin{abstract}
This article intends to analyze how the changes in the Technological Innovation Act affected exclusivity clauses in these agreements. The main target is to evaluate the presence of exclusivity clauses in contracts of technological cooperation. Methodologically, the institutional microanalysis, based on the idea of law as identity, is used as a methodological tool to evaluate the Technological Innovation Act so as to critically reconstruct the objectives of the transfer of technology from public to private agents, granted by the Act, regarding the values of a personified community in a context of public-oriented actions.
\end{abstract}

Keywords: Technological cooperation contracts, Technology transfer, Technological innovation, Law as identity

\footnotetext{
${ }^{1}$ Doutor em Direito pela Universidade Federal de Minas Gerais - UFMG, Belo Horizonte, (Brasil). Professor Associado da Universidade Federal de Juiz de Fora - UFJF, Juiz de Fora, Minas Gerais, Brasil. E-mail: mvchein@ gmail.com

${ }^{2}$ Mestrando em Direito pela Universidade do Estado do Rio de Janeiro - UERJ, Rio de Janeiro, (Brasil). Bolsista de Iniciação Científica pela Universidade Federal de Juiz de Fora - UFJF, Juiz de Fora, Minas Gerais, Brasil. E-mail: matheusandrade@outlook.com
} 


\section{INTRODUÇÃ̃O}

Os Contratos de Cooperação Tecnológica (CCT) permitem a aproximação das Instituições Científicas e Tecnológicas (ICT) com a iniciativa privada. Trata-se de um mecanismo jurídico que procura aproximar as entidades responsáveis pela maior parte das pesquisas realizadas no país do setor produtivo, que depende cada vez mais da inovação em um contexto de mercado cada vez mais competitivo. Por isso, estudar os CCT resulta em estudar o sistema de inovação do país, ou seja, compreender de que maneira a inovação tecnológica é regida pela legislação ao mesmo tempo em que seus resultados podem servir apenas aos setores produtivos ou, então, a toda comunidade em que este setor se insere.

Desta forma, este estudo propõe analisar de que maneira a lei 13.243 de 11 de janeiro de 2016, alterou o regime dos Contratos de Cooperação Tecnológica no que tange às cláusulas de exclusividade. Por meio da análise das alterações verificadas na lei, é possível conhecer os novos parâmetros jurídicos que irão se concretizar nas atividades de inovação no país. O desafio encontra-se em realizar uma interpretação que não leve em consideração apenas aspectos de uma economia de mercado, buscando compreender a lei também como mecanismo de emancipação e de valorização das disposições constitucionais relativas à inovação, que determinam a busca pelo desenvolvimento regional e pelo crescimento qualitativo da economia nacional.

Deste modo, esta pesquisa pode ser classificada como qualitativa baseada em traços de significação (unobstrusive research), de acordo com Babbie (2000). O método de análise de conteúdo é utilizado com o objetivo de se construir um sistema analítico de conceitos, essencial para se analisar a lei de inovação tecnológica, a Constituição Brasileira e as demais normas do ordenamento jurídico brasileiro.

Por meio da utilização de uma metodologia de análise empírica, foi possível verificar as alterações efetivadas na lei de inovação de maneira a se entender o objeto, a função e fundamentação dos artigos alterados objetos de estudo, quais sejam, aqueles que regulam as cláusulas de exclusividade nos CCTs de maneira direita ou indireta. Para isso, foi construída uma tabela com o objeto, função e fundamentação dos artigos coletados. Tais dados permitem que se compreenda de maneira sistemática as alterações que ocorridas na lei 10.973

\footnotetext{
${ }^{1}$ Este trabalho tem apoio financeiro da Fundação de Amparo à Pesquisa do Estado de Minas Gerais (FAPEMI) e do CNPq.
} 
assimilando qual será a nova configuração dos CCT no que tange a exclusividade de inventos de ICTs concedidas a um agente privado.

Para a análise das alterações legislativas, a utilização de um referencial teórico foi providencial, pois é este quem fornece o substrato necessário para a análise da lei e de seus institutos. Utiliza-se a teoria do Direito como Identidade, derivada da teoria de identidade do Self, de Charles Taylor(2011) complementada pela teoria do direito como integridade de Ronald Dworkin (2007) para tal tarefa. Taylor identifica que a identidade se expressa por meio dos selves, que interagem dentro de uma rede de interlocução, onde se estabelecem as avaliações fortes da vida que vale a pena ser vivida. Dworkin, por sua vez, identifica que o Direito deve ser íntegro na criação e aplicação das leis, concluindo que o Direito em si deve ser definido como uma prática interpretativa construtiva.

A regulamentação das cláusulas de exclusividade nos CCT realizada pela lei de inovação tecnológica consiste no objeto de estudo escolhido. Por meio dos dados coletados, opta-se por estudar a forma de regulamentação das referidas cláusulas presentes nos CCT firmados pelas ICTs, procurando entender se as disposições legislativas protegem as instituições públicas e efetiva os princípios constitucionais. Diante dos objetivos constitucionais de desenvolvimento econômico e tecnológico aliados ao interesse social ${ }^{2}$, visa-se compreender as cláusulas à luz do Direito como Identidade, buscando formas de se proteger o interesse público sem comprometer o competitividade do desenvolvimento tecnológico destas instituições, bem como sua inserção em um mercado global.

Este trabalho se dividirá em quatro partes principais. Primeiramente será explicada a estratégia metodológica deste estudo e o referencial teórico utilizado para interpretar os fragmentos escolhidos da lei de inovação tecnológica. Em seguida, apresenta-se a tabela com os artigos da lei $\mathrm{n}^{\circ} 10.973$, alterados pela lei $\mathrm{n}^{\circ} 13.243$, relevantes para a análise proposta. Na terceira parte os dados expostos na tabela serão explorados de maneira aprofundada, o que permitirá as conclusões deste estudo, presentes na derradeira parte.

\section{ESCOLHA METODOLÓGICA E FUNDAMENTAÇÃO TEÓRICA}

Pretende-se estudar as mudanças efetivadas na Lei de Inovação Tecnológica por meio da lei de $\mathrm{n}^{\mathrm{o}} 13.243$ de 11 de janeiro de 2016 no que diz respeito as cláusulas de exclusividade presentes em Contratos de Cooperação Tecnológica. Metodologicamente, utiliza-se uma

\footnotetext{
${ }^{2}$ CF/1988, Art. 218: “O Estado promoverá e incentivará o desenvolvimento científico, a pesquisa e a capacitação tecnológicas."
} 
técnica de pesquisa que interprete os dispositivos da lei por meio do tabelamento dos dados coletados, seguindo como referencial teórico o Direito como Identidade, que permite compreender a legislação e interpretar os dados utilizados.

Os Contratos de Cooperação Tecnológica se constituem como um mecanismo jurídico em que uma ICT, Instituição Científica e Tecnológica, e agentes privados se aliem no intuito de desenvolver novas tecnologias. Trata-se de uma forma de aproximar centros de pesquisa públicos dos agentes produtivos, o que permite uma maior flexibilidade à pesquisa no país no sentido tanto de cobrir gastos quanto de viabilizar a própria estrutura de pesquisas científicas. Inúmeros benefícios podem ser vistos nesses contratos como, por exemplo, a aproximação das ICT de empresas e agentes das regiões onde se encontram, o que permite um maior direcionamento às necessidades locais, à facilitação do financiamento das pesquisas, ao desenvolvimento da indústria e das empresas nacionais que passam a ter acesso a novas tecnologias, além de uma união de forças salutar entre entes públicos e privados sob o mesmo fim: a inovação. No entanto, os CCT são um mecanismo complexo, que envolvem inúmeros desafios atinentes tanto ao setor público quanto ao setor privado. Portanto, seu estudo necessita de uma compreensão do próprio cenário econômico e social no qual tanto ICT quanto empresas se inserem, não deixando de mencionar os pesquisadores, agentes fundamentais da pesquisa tecnológica.

Diante deste objeto de estudo, enfrenta-se o tema proposto por meio de uma metodologia que busca centrar-se na construção do campo científico do Direito. Utilizase do método como forma de acessar o objeto de estudo, compreendendo-o não apenas com o mero intuito de descrevê-lo. De acordo com Rubin (1997), o que distingue o direito de outros ramos do conhecimento é seu status epistemológico de prescritividade. Logo, procura-se não apenas acessar o objeto de estudo, mas utilizá-lo como meio de propor novos caminhos, uma reflexão que utiliza necessariamente esta característica do campo do Direito descrita por Rubin. Dessa forma, a interpretação da Lei $n^{0} 10.723$, realizada por meio do Direito como Identidade, o marco teórico deste trabalho, efetiva a atividade de interpretação com a capacidade epistomológica de prescritividade inerente ao Direito.

A fim de se alcançarem os objetivos deste estudo, faz-se necessária a construção de um sistema analítico de conceitos realizada por meio de uma pesquisa qualitativa a partir de traços de significação (BABBIE, 2000), que torna possível inferir se as alterações na lei de inovação buscaram efetivar princípios constitucionais de desenvolvimento tecnológico e social. Primeiramente, realiza-se o tabelamento dos artigos da lei $\mathrm{n}^{\circ} 10.723$ (com as alterações da Lei 13.243/16) que tratam das cláusulas de exclusividade em contratos de cooperação 
tecnológica. Em seguida, estes dados são interpretados seguindo os ideais do Direito como Identidade, resultado do alinhamento da teoria tayloriana de identidade do self com as propostas de Ronald Dworkin a respeito da Integridade no Direito, possibilitando interpretar os dados coletados de modo a compreender as alterações efetivadas na lei de inovação.

Este estudo se adequa ao que Rubin (1996b, p. 1495) denominou "microanálise institucional". O conceito de microanálise como metodologia reconhece o Direito como possuidor de uma coerência conceitual que o define como um ramo do conhecimento, sem desconsiderar suas possíveis conexões com as diferentes áreas do saber. O termo "microanálise" se refere à ênfase no particular. Por isso, este estudo se concentra especificamente nas cláusulas de exclusividade nos CCT, de modo a se realizar uma microanálise buscando compreender a forma de implantação de um mecanismo jurídico escolhido e selecionado pelo legislador. Essa especificidade, segundo Rubin (1996b), gera uma fundamentação de cunho empírico que, por sua vez, tende a gerar áreas de entendimento comum, traço necessário para uma metodologia unificada para o Direito.

Neste estudo o dado observado consiste nas cláusulas de exclusividade da lei de inovação tecnológica, uma evidência qualitativa que permite compreender se a própria lei efetiva princípios constitucionais de desenvolvimento tecnológico, protegendo instituições públicas de interesses meramente particulares e direcionando a pesquisa e a inovação do país de modo a não beneficiar apenas agentes específicos, mas a nação como um todo. Desse modo, é necessário refinar a pesquisa para que apenas os artigos que tratem dessas cláusulas dos contratos sejam analisados. O método escolhido para análise da lei foi o do tabelamento dos artigos que tratam das cláusulas de exclusividade. Este tabelamento permite uma análise mais pormenorizada das disposições legislativas, chegando-se a uma compreensão aprofundada do instituto jurídico estudado, bem como das possibilidades que a legislação abre a partir das alterações recentemente efetivadas.

Para tanto, o primeiro dado da tabela é o objeto de cada artigo. Neste campo buscou-se compreender de que se trata o trecho da lei em termos gerais, exibindo quem serão os agentes afetados por aquela disposição normativa. Eis aí um dado importante, pois permite compreender quem será atingido pelas mudanças na lei, quais os agentes que o legislador buscou proteger ou, mesmo, ordenar algum tipo de comportamento específico.

O segundo dado presente na tabela é a função dos dispositivos legais. Observa-se aqui a intenção do legislador para a disposição jurídica analisada, ou seja, o que buscou-se realizar por meio da lei, qual princípio constitucional ou, mesmo, da própria lei de inovação tentou-se 
concretizar. A importância aqui claramente é a de apontar quais princípios o legislador mais prestigiou. Portanto, é possível determinar que fins a atual lei buscou atingir e se o legislador escolheu o caminho mais adequado para efetivar a garantia que pretendeu implementar.

O terceiro dado da tabela é a fundamentação do dispositivo, a explicação para a presença daquela disposição na lei. Aqui, é necessário ressaltar que se analisa a lei de acordo com o Direito como Identidade, logo, a fundamentação sempre será de acordo com o marco teórico escolhido. Decerto, aqui se intentou compreender o status de prescritividade do campo do Direito de modo que os artigos são lidos e interpretados, buscando-se encontrar traços de significação que possuam elementos do marco teórico escolhido e utilizado.

Portanto, a tabela não é utilizada como mera forma de se explicar visualmente a lei. Os dados ali expostos refletem uma concepção teórica própria em que se constrói um verdadeiro sistema analítico de conceitos, fundamental ao processo de compreensão da lei. Para esta atividade, utiliza-se então o Direito como Identidade, que consiste na aproximação das ideias de Charles Taylor da construção de identidade individual com o Direito como Identidade de Ronald Dworkin.

Em As Fontes do Self, Taylor (2002) buscou retratar a construção da identidade do indivíduo por meio de configurações qualitativas axiológicas. Segundo o autor, não seria possível ao indivíduo a construção de sua própria identidade sem algum tipo de referencial moral. A construção do self ocorre através do que o autor chamou de avaliações fortes que se desenvolvem por meio das escolhas que o indivíduo realiza selecionando e hierarquizando seus desígnios para alcançar uma vida virtuosa. Segundo Taylor, só se é um self integral na medida em que se move num certo espaço de indagações, em que se busca e se encontra uma orientação para o bem (TAYLOR, 2002). Este espaço de indagações, para o autor, é um ambiente intersubjetivo onde o indivíduo se relaciona com seus demais interlocutores, ou seja, uma rede de interlocução onde o sujeito se articula por meio da linguagem e de seus valores morais.

Verifica-se que um texto normativo é fruto das escolhas realizadas pelo legislador. Entretanto, este texto é e sempre será reinterpretado por aqueles a quem a lei se destina. Para Taylor, a linguagem do self não é estática sendo sempre feita e refeita no âmbito da fala. De maneira correlata, Dworkin (2007) define que o Direito está sendo sempre construído por cada intérprete, já que cada indivíduo acrescenta algo a sua interpretação. Logo, a interpretação do texto legal não é estática, já que, por conta de um processo dialético e dialógico, há de evoluir em um âmbito intersubjetivo. 
Assim, a interpretação legal não é uma atividade de mero entendimento de uma prescrição dada pelo legislador, mas um ato no qual deve almejar-se concretizar o texto normativo, segundo os ideais de justiça. Para que a justiça seja alcançada nesse processo, é necessário que, por meio do que Taylor (2002) definiu como distinções qualitativas, realize-se uma orientação em direção aos bens que mais se aproximam daquilo que se considera como justo. O que distingue este caso dos demais é o caráter vinculante que o texto normativo possui. Sendo assim, os bens que não foram selecionados prioritariamente, não terão a força de vincular o comportamento das instituições e indivíduos regulamentados pela lei. Para Taylor (2002), vive-se em uma sociedade em que os bens estão frequentemente contrapostos e são necessárias diversas articulações entre as avaliações fortes para que se possa escolher a vida que vale a pena ser vivida, a vida com uma orientação para o bem. Dessa forma, deve-se priorizar alguns desígnios e deixar de lado outros, para que sejam alcançados os objetivos necessários a uma vida boa. No caso do direito, alguns "hiperbens", aqueles bens com importância superior em relação aos demais, terão de ser priorizados para que os ideais de justiça não sejam comprometidos.

No Direito como Identidade, vale considerar que a integridade pode ser apontada como um "hiperbem". Para Dworkin, a integridade no Direito exige a adequação da interpretação legal a um referencial moral da "comunidade personificada". Esta comunidade possui uma identidade própria, que se constitui previamente ao próprio indivíduo e que emana de seus próprios princípios os quais devem ser refletidos na Constituição da República. Dessa forma, ao criarem as leis, os legisladores devem se pautar de maneira coerente pelos princípios emanados da comunidade personificada. A rigor, os fundamentos da justiça dessa comunidade se estruturam num processo de consistência articulada a partir de valores expressos no contexto de uma Constituição. Assim sendo, é essencial se utilizar a lógica da integridade para se avaliar se os fundamentos de cada dispositivo legal revelam uma coerência com os valores essenciais dos princípios estruturados na Constituição Federal.

A tabela abaixo, permite a compreensão da legislação atual tanto em seu texto literal quanto em sua interpretação, realizada por meio do referencial teórico acima descrito. 


\begin{tabular}{|c|c|c|c|}
\hline Artigo & Objeto & Função & Fundamento \\
\hline $\begin{array}{l}\text { Art. 1o Esta Lei estabelece medidas de incentivo à pesquisa } \\
\text { científica e tecnológica no ambiente produtivo, com vistas à } \\
\text { capacitação tecnológica, ao alcance da autonomia } \\
\text { tecnológica e ao desenvolvimento nacional regional do } \\
\text { país, nos termos dos arts. 23, 24,167, 200, } 213,218,219 \text { e } \\
\text { 219-A da Constituição Federal. Parágrafo Único: As } \\
\text { medidas às quais se refere o caput deverão observar os } \\
\text { seguintes princípios: }\end{array}$ & $\begin{array}{l}\text { Delimitação do escopo da } \\
\text { lei10.973, tanto de seus } \\
\text { fundamentos quanto de } \\
\text { seus princípios }\end{array}$ & $\begin{array}{l}\text { Delimitar de maneira precisa a própria função da lei; onde } \\
\text { ela será utilizada e quais serão os princípios que deverão } \\
\text { ser observados no momento de sua aplicação. }\end{array}$ & $\begin{array}{l}\text { Procura-se efetivar de maneira mais } \\
\text { ampla o princípios que Constituição já } \\
\text { determin para a inovaçã tecnológica no país. }\end{array}$ \\
\hline $\begin{array}{l}\text { I - promoção das atividades científicas e tecnológicas como } \\
\text { estratégicas para o desenvolvimento econômico e social; }\end{array}$ & $\begin{array}{l}\text { Os contratos de } \\
\text { cooperação tecnológica, } \\
\text { seus agentes bem como os } \\
\text { objetos jurídicos } \\
\text { envolvidos neste contrato }\end{array}$ & $\begin{array}{l}\text { Garantir que a lei de inovação seja interpretada de modo } \\
\text { mais amplo. Decerto, busca-se efetivar um sistema de } \\
\text { inovação que não seja baseado apenas em regras } \\
\text { econômicas ou de mercado. Temos aqui o legislador } \\
\text { atuando no sentido de intervir de maneira mais acentuada } \\
\text { na inovação, possibilitando ao Estado atuar de forma } \\
\text { presente. }\end{array}$ & $\begin{array}{l}\text { Pretende-se que inovação tecnológic sirva aos } \\
\text { princípio constitucionais, a relaçã dos princípios } \\
\text { escolhido com princípios de sed constitucional é } \\
\text { evident Portanto, o fundament neste caso é o de } \\
\text { efetiva Constituição Feder ampliando } \\
\text { mecanismo que possam contribu para o } \\
\text { desenvolviment do país. }\end{array}$ \\
\hline $\begin{array}{l}\text { II - promoção e continuidade dos processos de } \\
\text { desenvolvimento científico, tecnológico e de inovação, } \\
\text { assegurados os recursos humanos, econômicos e financeiros } \\
\text { para tal finalidade; }\end{array}$ & $\begin{array}{l}\text { Regulamenta a maneira } \\
\text { pela qual os CCT deverão } \\
\text { ser firmados. }\end{array}$ & $\begin{array}{l}\text { Neste caso, nota-se uma expansão do escopo dos CCT. } \\
\text { Agora o inciso I prevê o compartilhamento não apenas } \\
\text { com empresas de pequeno porte, mas qualquer agente } \\
\text { privado envolvido com atividade de pesquisa e inovação } \\
\text { tecnológica. }\end{array}$ & $\begin{array}{l}\text { Aumenta possibilidades de interação entre ICTs } \\
\text { agentes privados. Retiro se a menção exclusiva } \\
\text { pequenas e médias empresas no inciso I, e } \\
\text { empresas nacionais n inciso II. Portanto } \\
\text { percebe-se um maior foc na inovação em si e nã } \\
\text { apenas desenvolvimento de indústrias e } \\
\text { empresas d segmentos específicos. }\end{array}$ \\
\hline
\end{tabular}




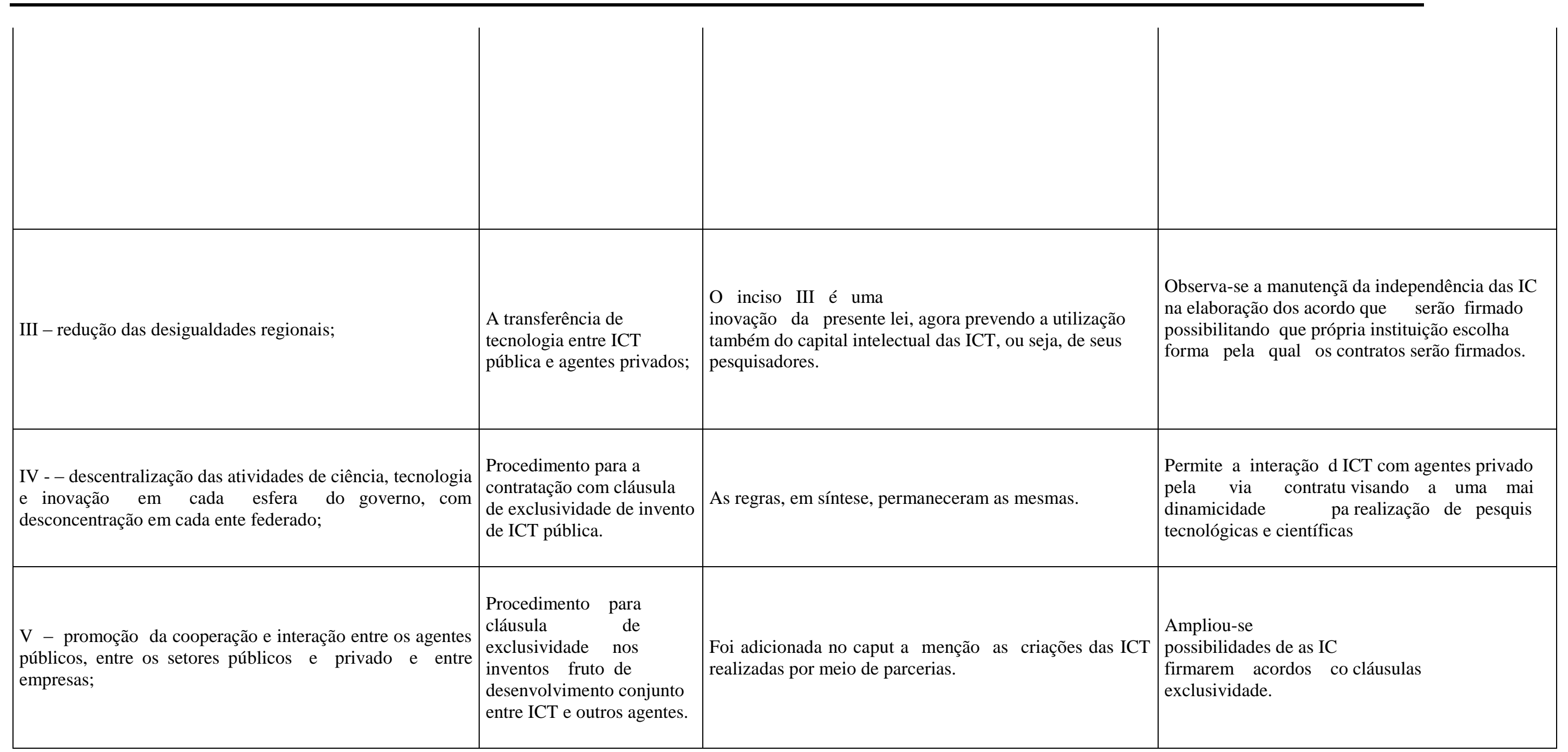


VI - estímulo à atividade de inovação nas Instituições Cientifica, Tecnológica e de Inovação (ICT) e nas empresas, Prestação de serviços inclusive para a atração, a constituição e a instalação de especializados por

centros de pesquisa, desenvolvimento e inovação e de ICTs parques e polos tecnológicos no país; pública mas sem especificar o meio pelo qual se dará

escolha.

Acordos de parceria privados

A oferta pública passa a ser dispensada para a exclusividade na exploração de invento fruto de desenvolvimento comum. entre ICTs e agentes

Especifica o retorno

VIII - incentivo a constituição de ambientes favoráveis à financeiro dos agentes inovação e às atividades de transferência de tecnologia;

envolvidos nos acordo de parceria.

IX - promoção e continuidade dos processos de formação e capacitação cientifica e tecnológica;

ta titularidadedos inventos

$\mathrm{X}$ - fortalecimento das capacidades operacional, cientifica, tecnológica e administrativa das ICTs;

Permitir às ICT que prestem serviços

relacionados a inovação científica a

outras instituições.

Estabelece a possibilidade de a ICT realizar pesquisas em conjunto com outras instituições por meio de acordos.

Não houve maiores alterações.

Ampliou-se aqueles que poderão ter direito a bolsas de
A proporção dos ganhos relativos ao contrato. estímulo, agora abrange-se também alunos de cursos

técnicos, graduação e pós graduação.

Amplia-se a liberdade $\mathrm{d}$

ICTs com o prováy

intuito de atrair ma agentes privados para CCTs.

\section{Reconhecimento}

Visa a garantir que as IC

possam se relacionar com outras instituiçõ

utilizando-se de s capacidade para fins inovação.

Garante que os benefíci financeiros advindos d CCT sejam concedidos todos aqueles envolvid na

concretização d contrato.

necessidade de as IC interagirem com outr

instituições para o avanç da pesquisa científica. 


\begin{tabular}{|c|c|c|c|}
\hline $\begin{array}{l}\text { XI - atratividade dos instrumentos de fomento e de crédito, } \\
\text { bem como sua permanente atualização e aperfeiçoamento; }\end{array}$ & $\begin{array}{l}\text { Natureza jurídica da bolsa } \\
\text { de estímulo dos } \\
\text { pesquisadores. }\end{array}$ & $\begin{array}{l}\text { Sem maiores alterações, prescreve a necessidade de } \\
\text { previsão contratual de quem será o titular dos resultados } \\
\text { das criações da parceria. }\end{array}$ & $\begin{array}{l}\text { Assegura o direito propriedade intelectual e } \\
\text { participação nos resultados. }\end{array}$ \\
\hline $\begin{array}{l}\text { XII - simplificação de procedimento para gestão de projetos } \\
\text { de ciência, tecnologia e inovação e adoção de controle por } \\
\text { resultados em sua avaliação; }\end{array}$ & $\begin{array}{l}\text { Direitos de cessão } \\
\text { da ICT sobre a criação para } \\
\text { o inventor, a título gratuito. }\end{array}$ & $\begin{array}{l}\text { Novamente flexibilizaram-se as exigências. Agora não se } \\
\text { exige uma proporção relativa ao valor agregado do } \\
\text { conhecimento. }\end{array}$ & $\begin{array}{l}\text { Trata-se de um nítid incentivo as empresa } \\
\text { Sem a proporção quant ao conhecimento, } \\
\text { possível que o retorn seja medido quanto a } \\
\text { investimento econômic o que garantirá mai } \\
\text { retorno a quem invest mais, geralmente, agente } \\
\text { privado. }\end{array}$ \\
\hline $\begin{array}{l}\text { XIII - utilização do poder de compra do Estado, para } \\
\text { fomento à inovação }\end{array}$ & $\begin{array}{l}\text { Direitos de ganho do } \\
\text { inventor. }\end{array}$ & $\begin{array}{l}\text { Protege a previdência e também as empresas de possíveis } \\
\text { ações quanto a natureza empregatícia dos pesquisadores. }\end{array}$ & $\begin{array}{l}\text { Novamente um incentiv às empresas que ago } \\
\text { estão garantidas quanto possíveis ações } \\
\text { trabalhistas e ao própri governo, que protege } \\
\text { Previdência Social }\end{array}$ \\
\hline $\begin{array}{l}\text { XIV - apoio, incentivo e integração dos } \\
\text { inventores independentes às atividades } \\
\text { das ICTs e ao sistema produtivo; }\end{array}$ & & $\begin{array}{l}\text { Permite que o inventor exerça os direitos sobre a criação a } \\
\text { título não oneroso nos casos em que a ICT assim o } \\
\text { permitir. Não houve maiores alterações }\end{array}$ & $\begin{array}{l}\text { Assegura que o invent possa exercer se } \\
\text { direitos sobre sua criaçã a título gratuito caso } \\
\text { ICT permita. }\end{array}$ \\
\hline $\begin{array}{l}\text { Art. 4o A ICT poderá, mediante contrapartida financeira } \\
\text { ou não financeira, nos termos de contrato ou convênio: }\end{array}$ & & $\begin{array}{l}\text { Garante o direito do inventor de receberuma } \\
\text { porcentagem dos ganhos que suainvenção gerar. Não } \\
\text { houve maiores alterações. }\end{array}$ & $\begin{array}{l}\text { Assegurar o direito fundamental do inventde } \\
\text { ser reconhecido p seu trabalho. }\end{array}$ \\
\hline
\end{tabular}


I - compartilhar seus laboratórios, equipamentos, instrumentos, materiais e demais instalações

com ICT ou empresas em ações voltadas à

inovação tecnológica para consecução das atividades de incubação, sem

prejuízo de sua atividade finalística,

prejuizo de sia aividade finglís

II - permitir a utilização de seus laboratórios, equipamentos, instrumentos, materiais e demais instalações existentes em suas próprias dependências por ICT, empresas ou pessoas físicas voltadas a atividades de pesquisa, desenvolvimento e inovação, desde que tal permissão não interfira diretamente em sua atividade-fim, nem com ela conflite.

III - permitir o uso de seu capital intelectual em projetos de pesquisa, desenvolvimento e inovação; Parágrafo único. O compartilhamento e a permissão de que tratam os incisos I e II do caput deste artigo obedecerão às prioridades, critérios e aos requisitos aprovados e divulgados pela ICT pública, observadas as respectivas disponibilidades $\mathrm{e}$ assegurada a igualdade de oportunidades a empresas e demais organizações interessadas Art. 6o É facultado à ICT pública celebrar contratos de transferência de tecnologia e de licenciamento para outorga de direito de uso ou de exploração de criação por ela desenvolvida isoladamente ou por meio de parceria.

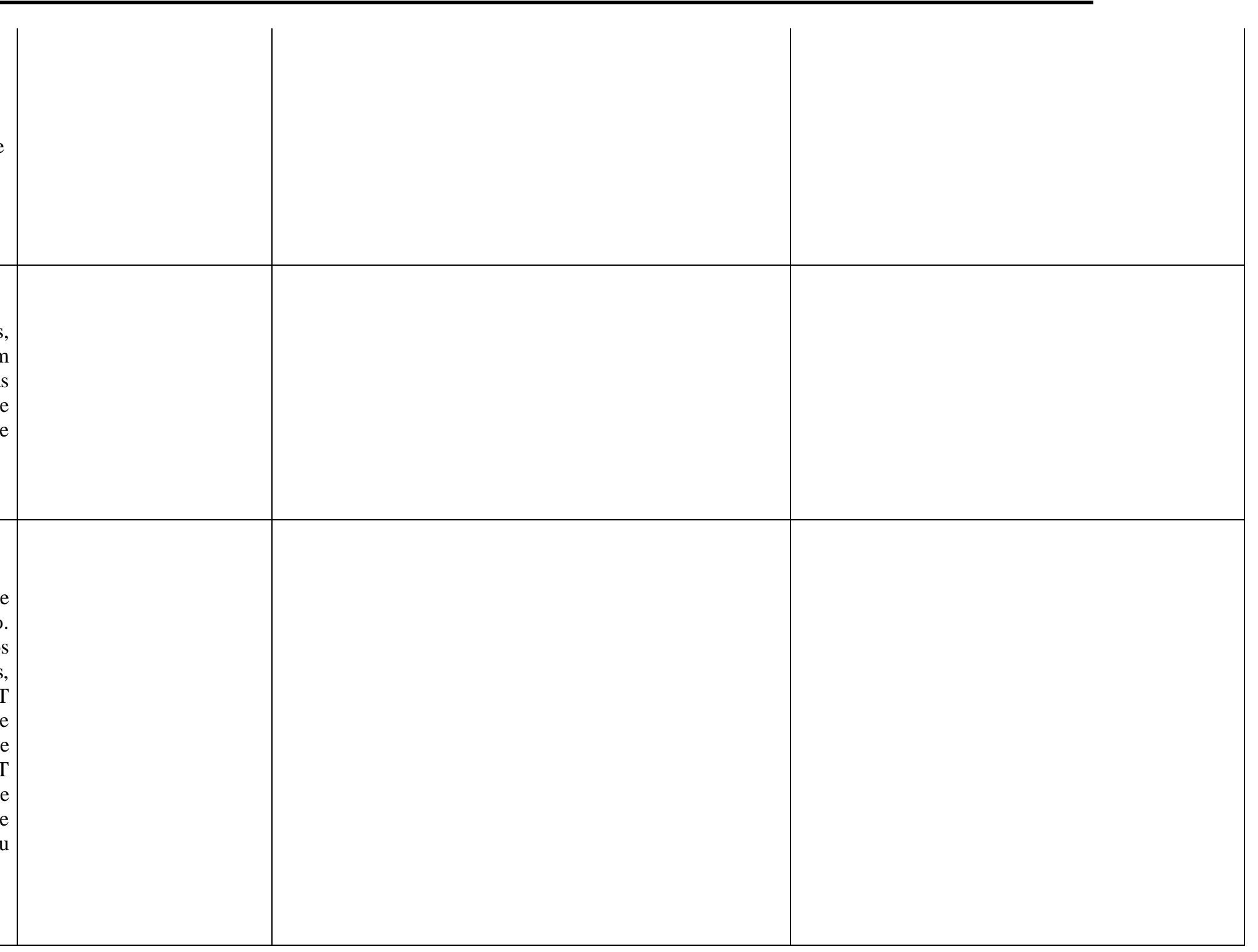


$\S 1^{\circ}$ - A contratação com cláusula de exclusividade, para os fins de que trata o caput, deve ser precedida da publicação de extrato da oferta tecnológica em sítio eletrônico oficial da ICT, na forma estabelecida em sua política de inovação ;

$1 \S \mathrm{A}-$ No caso de desenvolvimento conjunto

com empresa, essa poderá ser contratada com cláusula de exclusividade, dispensada a oferta pública, devendo ser estabelecida em

convênio ou contrato a forma de remuneração.

Art. 80 É facultado à ICT prestar a instituições públicas ou privadas serviços técnicos especializados compatíveis com os objetivos desta Lei, nas atividades voltadas à inovação e à pesquisa científica e tecnológica no ambiente produtivo, visando, entre outros objetivos, à maior competitividade das empresas.

§ 1o A prestação de serviços prevista no caput dependerá de aprovação pelo representante legal máximo da

instituição, facultada a delegação a mais de uma autoridade,

e vedada a subdelegação.

\section{Art. 9o É facultado à ICT}

celebrar acordos de parceria com instituições públicas e

privadas para realização de atividades conjuntas de

pesquisa científica e tecnológica e de desenvolvimento de

tecnologia, produto, serviço ou processo.

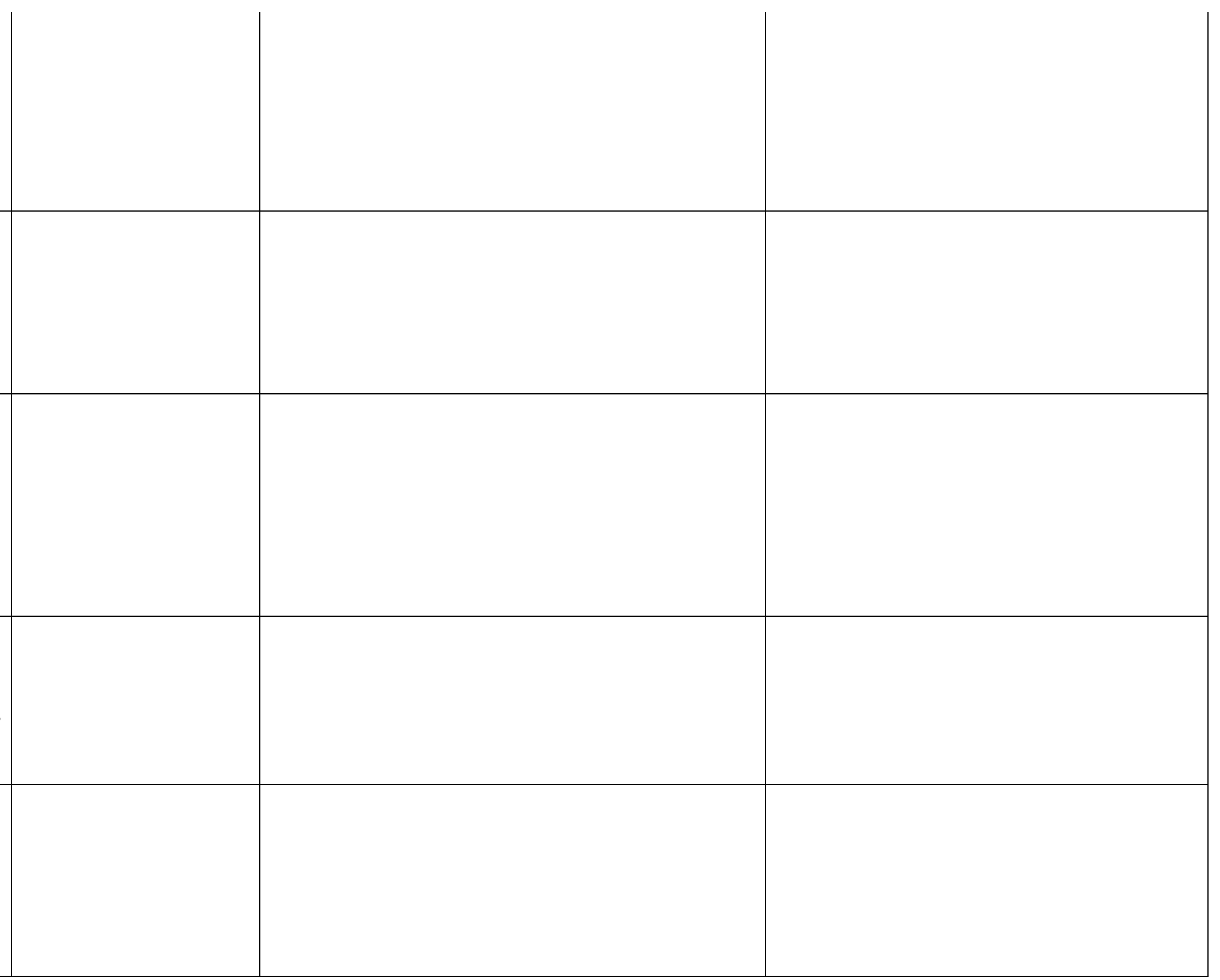


$\S 1$ o O servidor, o militar ou

o empregado público da ICT pública e o aluno de curso técnico, de graduação ou de pós-graduação

envolvidos na execução das atividades previstas no caput poderão receber bolsa de estímulo à inovação diretamente da ICT a que estejam vinculados, de fundação de apoio ou de agência de fomento.

$\S 20$ As partes deverão

prever em instrumento jurídico específico a titularidade da propriedade intelectual e a participação nos resultados da exploração das criações resultantes da parceria,

assegurando aos signatários o direito à exploração, ao

licenciamento e à transferência de tecnologia, observado o

disposto nos $\S \S 40$ a 60 do art. 7.

$\S 30$ A propriedade intelectual e a participação nos resultados referidas no $\S 20$ serão asseguradas às partes contratantes, nos termos do contrato, podendo a ICT ceder ao parceiro privado a totalidade de direitos de propriedade intelectual mediante compensação financeira ou não financeira, desde que economicamente mensurável.

$\S 4^{\circ} \mathrm{A}$ bolsa concedida nos termos deste artigo caracterizase como doação, não configura vínculo empregatício, não caracteriza contraprestação de serviços nem vantagem para o doador, para efeitos do disposto no art. 26 da lei $\mathrm{n}^{\circ} 9.250$, de 26 de dezembro de 1995, e não integra a base de cálculo da contribuição previdenciária, aplicando-se o disposto neste parágrafo a fato pretérito, como previsto no inciso I, do art, 106 da Lei n 5.172 de 25 de outubro de 1966.

\begin{tabular}{|l|l|l|}
\hline & & \\
\hline & & \\
\hline & & \\
\hline & & \\
\hline & & \\
\hline
\end{tabular}




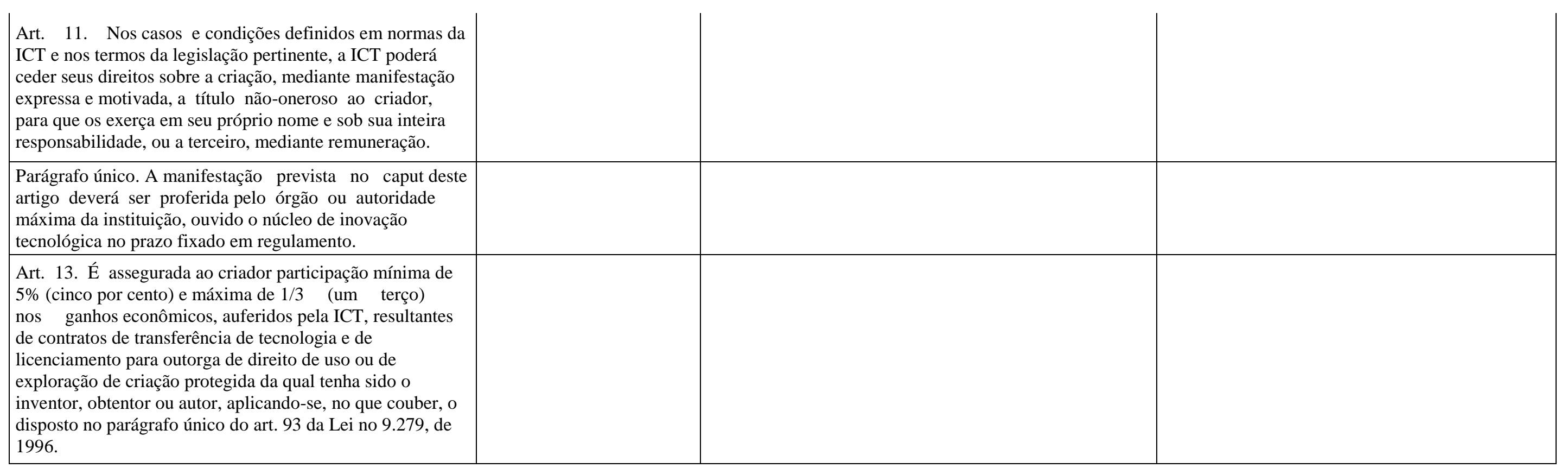

\section{RELAÇÃO ENTRE A REGULAMENTAÇÃO DOS CONTRATOS DE COOPERAÇÃO TECNOLÓGICA PELA LEI DE INOVAÇÃO TECNOLÓGICA E AS CLÁUSULAS DE EXCLUSIVIDADE}

O estudos das alterações legislativas da lei de inovação deixa claro o intuito de flexibilizar os contratos de cooperação tecnológica

permitindo que as ICTs e os agentes privados negociem de maneira mais livre as cláusulas dos contratos. Buscou-se ampliar os 
incentivos para que agentes privados invistam em inovação, permitindo um maior retorno econômico para estes agentes. Essa conclusão principal pode ser lida de diversas formas, sendo possível compreender, por exemplo, que o Estado abriu mão de ser o grande incentivador da pesquisa e da inovação, conferindo ao mercado a tarefa de financiar as pesquisas. Todavia, trata-se de uma leitura superficial do cenário da inovação tecnológica.

A flexibilização dos acordos por si só resulta em acordos prejudiciais para as ICTs e os pesquisadores de instituições públicas. É necessário interpretar a lei de modo a entender se as disposições jurídicas levaram em consideração o desenvolvimento da pesquisa e inovação no país ou se o objetivo foi o de auxiliar o setor privado a ter acesso a novas tecnologias. Neste último caso, certamente teríamos um prejuízo incontornável para o sistema de inovação, pois de fato existem interesses possivelmente divergente entre agentes privados e pesquisadores.

No artigo primeiro, foi especificado de maneira inédita os princípios da lei de inovação. Como visto na tabela, as especificações visaram prever também no âmbito infraconstitucional os princípios que a Constituição já estabeleceu como cogentes do sistema nacional de inovação. Não se trata de meras disposições acessórias, mas de uma verdadeira ferramenta jurídica de análise e compreensão da lei. Portanto, os incisos do artigo $1^{\circ}$ devem ser vistos como verdadeiras balizas da aplicação da lei. Desse modo, compreende-se que não houve uma flexibilização total da lei e dos CCT. Na verdade, buscou-se ampliar os mecanismos jurídicos de parceria entre agentes públicos e privados mas, ao mesmo tempo, aumentou-se o substrato de direitos e fins a que a lei serve. Logo, por serem princípios aplicáveis a toda a lei de inovação, também devem ser efetivados no âmbito dos CCT. Trata- se de uma previsão específica e taxativa da necessidade de promoção da redução das desigualdades regionais, da descentralização das atividades de ciência e tecnologia, da cooperação entre diversos entes públicos, dentre outros fins.

No artigo $4^{\circ}$ foram ampliadas as possibilidades de entes privados pelos quais as ICT poderão se aliar nos CCT. Foi retirada a menção a pequenas e médias empresas de modo a abarcar todo e qualquer ente privado. Constata-se uma preocupação em amplificar as possibilidades de parcerias entre ICTs e entes privados. Ao mesmo tempo nota-se no parágrafo primeiro do artigo sexto que o legislador não se preocupou em estabelecer quaisquer tipo de exigências quanto a oferta pública de inventos desenvolvidos por ICTs. Na verdade torna-se mais destacada a disposição que confere às ICTs maior liberdade para deliberar sobre o modo de licenciamento dos inventos bem como a fixação de cláusulas de exclusividade nos CCT. Inclusive foi adicionado o parágrafo 1- A em que passa a ser 
permitida expressamente a possibilidade de afastamento da oferta pública nos casos de inventos resultados de parceria. Dessa forma, o instituto do CCT agora possui maior atratividade para agentes privados, pois os inventos derivados do contrato poderão ser explorados pelo agente privado de maneira exclusiva, o que pode ser previsto no próprio CCT de maneira prévia, pois a legislação conferiu maior liberalidade para os entes públicos deliberarem internamente o conteúdo dos contratos.

No primeiro parágrafo do artigo nono constata-se outra previsão que visa conferir maior segurança jurídica aos agentes privados. Estabelece-se taxativamente que as bolsas de auxílio recebidas por pesquisadores não possui caráter de vínculo trabalhista, o que afasta qualquer tipo de possibilidade de questionamento no Poder Judiciário da natureza jurídica do vínculo existente entre os pesquisadores das ICTs e as empresas participantes dos CCTs. No terceiro parágrafo do mesmo artigo o legislador flexibilizou a divisão dos resultados dos CCTs, sendo extinta a previsão de divisão conforme o conhecimento de cada agente. Portanto, passará a valer de maneira preponderante o investimento financeiro nos CCTs o que, sem dúvida será um outro grande incentivo para o investimento privado em pesquisa e inovação.

É de se ponderar que o legislador de fato se preocupou em prever de maneira expressa no texto legal os princípios que devem reger a interpretação da lei de inovação. Estes princípios conferem um substrato interpretativo que possibilita implantar a lei de inovação de modo a assegurar os interesses das ICTs nos CCTs. Portanto, as alterações referentes às cláusulas de exclusividade não devem ser vistas como meros instrumentos de facilitação do financiamento privado das pesquisas. Na verdade, ao se ampliar os meios de financiamento assegura-se maior independência as ICTs, pois estas podem escolher a que financiamento recorrer. Todavia, por esta mesma razão o afastamento da necessidade de oferta pública nos casos de produtos resultado de parcerias, não é salutar. Tanto a ICT quanto o agente privado seriam beneficiados pela oferta pública caso de fato esta opção seja a mais viável economicamente. Afastar a oferta pública diminui a transparência e aumenta as possibilidade de os CCTs não passarem por um necessário controle público por parte tanto da sociedade quanto da própria comunidade científica.

Desse modo, passa a ter maior relevância a maneira pela qual a ICTs irão deliberar internamente pela realização dos CCTs. Se o legislador abriu maior possibilidade e uma flexibilização para a realização de parcerias, será no âmbito das instituições públicas que o controle deverá ser realizado de maneira mais detalhada. O próprio aumento do financiamento privado que a lei pode vir a gerar tornará ainda mais necessária a fiscalização desses contratos e dos recursos empregados nas pesquisas, bem como da utilização de bens públicos nas 
pesquisas. Não é possível conceber que a pesquisa e a inovação sejam direcionadas única e exclusivamente para absorver a necessidade individual de indústrias ou setores das atividades econômicas.

O meio de se realizar a fiscalização e controle dos CCT e da utilização das cláusulas de exclusividade é claro: a efetivação dos princípios previstos no artigo primeiro, que não devem ser vistos como apenas institutos laterais e de menor importância da lei. Os princípios são, na verdade, o reflexo direto dos anseios de uma comunidade personificada e da escolhas tangíveis resultados da construção da identidade nacional. Portanto, ao se falar dos contratos de cooperação tecnológica e das cláusulas de exclusividade destes contrato, não se deve mencionar apenas os poucos artigos que regulamentaram estes dispositivos de maneira aberta e ampla. Os princípios da lei devem obrigatoriamente fazer parte dos contratos, tanto em seus fins quanto na sua própria concepção.

A tecnologia deve ser instrumento de emancipação e liberdade, por isso mesmo um sistema de inovação deve, de fato, ser aberto a novos meios de interação entre diferentes atores sociais. A maneira de efetivar a capacidade emancipatória da inovação é alia-la aos princípios de uma comunidade personificada. Trata-se de não considerar apenas o progresso tecnológico em si mesmo, algo que o mercado pode realizar sem se utilizar de instituições públicas. Na verdade, os princípios da lei de inovação, que são na verdade a inovação da lei em si, devem servir de filtro para a construção de um direito sensível às dificuldades e precariedades da sociedade civil como um todo, excluindo os grupos de interesses de setores interessados em um sistema de inovação desenvolvimentista, útil apenas para aqueles escolhidos como beneficiários de uma exclusividade a qual acaba por se tornar excludente.

\section{CONCLUSÃO}

Por meio do referencial teórico do Direito com Identidade, fruto das ideias de Taylor (2006) e Dworkin (2011), analisa-se como as alterações da lei de inovação tecnológica criam um novo espectro jurídico para os Contratos de Cooperação Tecnológica e para as cláusulas de exclusividade presentes nestes acordos. Partindo de uma metodologia cuja análise da lei identificou o objeto, a função e a fundamentação de cada dispositivo da lei $\mathrm{n}^{\circ} 10.973$, alterada pela Lei $n^{\circ} 13.243$, estabelece-se de maneira ordenada como os dispositivos legais criam um novo cenário legal para a efetivação dos CCTs. 
A reconstrução crítica dos mecanismos jurídicos identificados na lei de inovação permite encontrar meios de se efetivar os princípios de uma comunidade personificada no âmbito da inovação tecnológica. A tabela demonstra como a legislação avançou ao prever de maneira expressa quais princípios devem ser observados no momento de interpretação da lei. Se, por um lado, a tendência de flexibilização das exigências legais foi preponderante, por outro, aumentouse a capacidade de controle público dos contratos, pois agora o aplicador da lei possui um meio direto de implantar os princípios constitucionais da inovação tecnológica nos próprios CCTs. Portanto, as cláusulas de exclusividade, ao serem previstas de maneira aberta, sem maiores exigências por parte do legislador, não passam a ser mecanismos de maior lucratividade de agentes privados. A lei é clara ao estabelecer que o desenvolvimento regional e nacional é um de seus fins e que a descentralização das atividades de pesquisa deve ser privilegiada. Estas previsões não são acessórias, devendo, pois, fazer parte de todos os CCT, bem como de todas as cláusulas de exclusividade.

A preservação dos desígnios constitucionais no plano da inovação é a melhor maneira de se privilegiar as necessidades socioculturais da comunidade no desenvolvimento das políticas e dos projetos de pesquisa e inovação essenciais às demandas da sociedade brasileira. Trata-se, enfim, do desafio de efetivar os princípios expressos não apenas como abstrações, mas como obrigações taxativas da inovação tecnológica no país.

\section{REFERÊNCIAS}

BABBIE, Earl. The practice of social research. 9. ed. Belmont Wadsworth/Thomson Learning, 2000.

BARBOSA, Denis Borges. Contratos de propriedade industrial e transferência de tecnologia. Disponível em: <www.denisbarbosa.addr.com>. Acesso em: 25 de julho de 2014.

BRASIL. Constituição Federal (1988). Constituição da República Federativa do Brasil. Brasília, DF, Senado, 1988. Disponível em: <http://www.planalto.gov.br/ccivil_03/constituicao/constituicaocompilado.htm>. Acesso em: 28 de julho de 2014.

Lei $n^{\circ} 10.973$, de 2 de dezembro de 2004. Dispõe sobre incentivos à inovação e à pesquisa científica e tecnológica no ambiente produtivo e dá outras providências. Brasília, df, 2004. Disponível em <http://www.planalto.gov.br/ccivil_03/_ato2004-

2006/2004/lei/110.973.htm>. Acesso em 28 de julho de 2014. 
DWORKIN, Ronald. O império do direito. Trad. Jefferson Luiz Camargo. 2. ed. São Paulo: Martins Fontes, 2007.

\section{2. \\ Levando os direitos a sério. Tradução Nelson Boeira. São Paulo: Martins Fontes,}

EPSTEIN, Lein; KING, Gary; The Rules of Inference; University of Chicago Law Review, vol. 69; 2002.

FERES, M. V. Chein Law, Art and Life: a critique of economic analysis of law based on integrity. In: Festival of Legal Theory, Edindurgh. IVR UK Conference http://www.law.ed.ac.uk/festivaloflegaltheory/files/paperivruk.pdf, 2008.

FERES, Marcos Vinício Chein; MENDES, Brahwlio Soares de Moura Ribeiro. Direito como identidade: Estado, direito e política. In: As novas faces do ativismo judicial. Salvador: JusPODIVM, 2011.

FERES, Marcos Vinicio Chein; NUNES, Victor Freitas Lopes. Direito como integridade e inovação: o caso dos fármacos de segundo uso. XXI Encontro Nacional do CONPEDI. 2012, Uberlândia. Anais. Disponível em: <http://www.publicadireito.com.br/artigos/?cod=74071a673307ca74>. Acesso em: 25 de julho de 2014.

FERES, Marcos Vinicio Chein; OLIVEIRA, Ludmila Esteves; Direito como identidade e inovação: uma análise necessária dos parques tecnológicos e contratos de cooperação tecnológica; XXII Encontro Nacional do CONPEDI. 2013, São Paulo. Anais. Disponível em: http://www.publicadireito.com.br/artigos/?cod=9246eb8610d571d9 Acesso em: 30 de julho de 2014.

REVEZT, Richard L.; A Defense os Empirical Legal Scholarship. The University of Chicago Law Review, vol. 69, 2002.

RUBIN, Edward. Law and the Methodology of Law. Wisconsin Law Review, pp. 541-565, 1997. Disponível em:

http://heinonline.org/HOL/Page?collection=journals\&handle=hein.journals/wlr1997\&div=30\&id $=$ \&page $=$. Acesso em: 29 julho de 2014 .

RUBIN, Edward. Public Choice and Legal Scholarship. Journal of Legal Education, vol. 46, p. 490, 1996a. Disponível em:

$<$ http://heinonline.org/HOL/Page?public=false \&handle=hein.journals/jled46\&men_hide=false \&m en_tab=toc\&collection=journals\&page=490>. Acesso em: 29 de julho de 2014 .

RUBIN, Edward. The New Legal Process, the Synthesis of Discourse, and the Microanalysis of Institutions. Harvard Law Review, vol. 109, n. 6, p. 1424-1438, Apr., 1996b. Disponível em: <http://www.jstor.org/stable/1342220>. Acesso em: 29 de julho de 2014.

RUBIN, Edward L. The Practice and Discourse of Legal Scholarship. Michigan Law Review, vol. 86, n. 8, p.1891-1905, Aug. 1988. Disponível em: <http://www.jstor.org/stable/1289072>. Acesso em: 29 de julho de 2014. 
TAYLOR, Charles. As fontes do self: a construção da identidade moderna. Trad. Adail Ubirajara Sobra e Dinah de Abreu Azevedo. 3 ed. São Paulo: Loyola, 2011.

UNGER, Mangabeira. Democracia realizada: a alternativa progressista. São Paulo: Boitempo Editorial, 1998.

WORLDBANK; Research and development expenditure (\% of GDP). Disponível em: http://data.worldbank.org/indicator/GB.XPD.RSDV.GD.ZS; Acesso em 28 de julho de 2014. 